\title{
Toll-like receptor-4 agonist in post-haemorrhage pneumonia: role of dendritic and natural killer cells
}

\author{
Antoine Roquilly ${ }^{1,2}$, Alexis Broquet ${ }^{1}$, Cedric Jacqueline ${ }^{1}$, Laetitia Gautreau ${ }^{3,4}$, \\ Jean Pierre Segain ${ }^{5}$, Pierre de Coppet $^{5}$, Jocelyne Caillon ${ }^{1}$, Frédéric Altare ${ }^{6}$, \\ Regis Josien ${ }^{3,4,7}$ and Karim Asehnoune ${ }^{1,2}$
}

\begin{abstract}
Affiliations: 'Laboratoire UPRES EA 3826 "Thérapeutiques cliniques et expérimentales des infections", Faculté de Médecine, Université de Nantes, Nantes, ${ }^{2} \mathrm{CHU}$ Nantes, Pôle Anesthésie Réanimations, Service d'Anesthésie Réanimation chirurgicale, Hôtel Dieu, Nantes, ${ }^{3}$ INSERM UMR1064 “Centre de Recherche en Transplantation et Immunologie" Nantes, Nantes, "CHU Nantes, Institut de Transplantation-UrologieNéphrologie (ITUN), Nantes, "Unité Mixte de Recherche 1280 "Physiologie des Adaptations Nutritionnelles", Institut National de Recherche Agronomique, Université de Nantes, Nantes, ${ }^{6}$ INSERM, Unité 892, Institut de Recherche Thérapeutique, Université de Nantes, Nantes, and ${ }^{7} \mathrm{CHU}$ Nantes, Laboratoire d'Immunologie, Nantes, France.
\end{abstract}

Correspondence: K. Asehnoune, CHU de Nantes, Service d'Anesthésie Réanimation, 1 place Alexis Ricordeau, 44093 Nantes, Cedex 1, France. E-mail: karim.asehnounedachu-nantes.fr

ABSTRACT Haemorrhage-induced immunosuppression has been linked to nosocomial infections. We assessed the impact of monophosphoryl lipid A, a Toll/interleukin-1 receptor-domain-containing adaptor protein inducing interferon-biased Toll-like receptor-4 agonist currently used as a vaccine adjuvant in humans, on post-haemorrhage susceptibility to infection.

We used a mouse model of post-haemorrhage pneumonia induced by methicillin-susceptible Staphylococcus aureus. Monophosphoryl lipid A was administered intravenously after haemorrhage and before pneumonia onset.

Haemorrhage altered survival rate, increased lung damage (neutrophil accumulation, oedema and cytokine release) and altered the functions of dendritic and natural killer cells. Here, we show that monophosphoryl lipid A decreased systemic dissemination of S. aureus and dampened inflammatory lung lesions. Monophosphoryl lipid A partially restored the capacity for antigen presentation and the transcriptional activity in dendritic cells. Monophosphoryl lipid A did not restore the interferon- $\gamma$ mRNA but prevented interleukin-10 mRNA overexpression in natural killer cells compared with untreated mice. Ex vivo monophosphoryl lipid A-stimulated dendritic cells or natural killer cells harvested from haemorrhaged animals were adoptively transferred into mice undergoing post-haemorrhage pneumonia. Stimulated dendritic cells (but not stimulated natural killer cells) improved the survival rate compared with mice left untreated. In vivo depletion of natural killer cells decreased survival rate of monophosphoryl lipid A-treated mice.

Dendritic and natural killer cells are critically involved in the beneficial effects of monophosphoryl lipid A within post-haemorrhage pneumonia.

@ERSpublications

Dendritic cells and NK cells are critically involved in the beneficial effects of MPLA within posthaemorrhage pneumonia http://ow.ly/oc4Zp

This article has supplementary material available from www.erj.ersjournals.com

Received: Sept 252012 | Accepted after revision: Dec 20 2012 | First published online: Jan 112013

Support statement: This work was supported only by institutional funds.

Conflict of interest: None declared.

Copyright (OERS 2013 


\section{Introduction}

Trauma is a major risk factor for nosocomial pneumonia in critically ill patients. Nosocomial pneumonia develops in $30-50 \%$ of trauma patients, mainly within the first week, and increases both the length of stay in the intensive care unit and the risk of death [1]. Methicillin-susceptible Staphylococcus aureus (MSSA) is the main pathogen involved in post-traumatic pneumonia [2]. This post-traumatic susceptibility to sepsis has been related to a state of immunosuppression lasting 7-10 days followed by an immunological recovery [3]. Dendritic cells (DCs) play a major role in linking innate and adaptive immune responses through production of cytokines, as well as presentation of antigen to naive lymphocytes [4]. Natural killer (NK) cells contribute to the anti-bacterial response, particularly through cytotoxic activity against infected cells and production of cytokines [5]. A defect in early activation of NK cells functions was associated with an impaired antibacterial response in brain-injured mice and patients [6]. Collaboration of DCs and NK cells is critical for the control of pathogen burden before adaptive immunity is fully activated [7]. Alterations of the cross-talk between DCs and NK cells may thus be involved in the post-traumatic susceptibility to infection.

Toll-like receptors (TLRs) are the best-characterised receptors that have evolved to recognise bacteria and to initiate immune response. TLR agonists are promising therapy for the prevention of infectious diseases in humans [8]. Monophosphoryl lipid A (MPLA), a truncated lipopolysaccharide, is a Toll/interleukin-1 receptor-domain-containing adaptor protein inducing interferon (TRIF)-biased TLR4 agonist that is commonly used as a vaccine adjuvant in human [9]. The TLR4/TRIF pathway stimulates the transcription of type I interferon (IFN), inducing the maturation of DCs and NK cells, and of interleukin (IL)-12, which enables the cross-activation of DCs and NK cells [10].

We have previously demonstrated that MPLA restores IL12p40 transcription in CD11c+ cells after haemorrhage [11]. DCs and NK cells are the two main subsets of CD11c+ cells and, in the present mechanistic study, we hypothesised that the beneficial effects of MPLA could be mediated by a direct stimulation of either DCs or NK cells. To test this hypothesis, we assessed the effects of MPLA on lung injuries and on the functions of conventional DCs (cDCs), plasmacytoid DCs (pDCs) and NK cells. Finally, we performed DC and NK cell adoptive transfer to delineate the respective role of DCs and NK cells in the response to MPLA. We used a model that mimics the clinical scenario of a severe trauma patient presenting with haemorrhagic shock and subsequent $S$. aureus nosocomial pneumonia. Haemorrhage has been previously demonstrated to reproduce the main features of human post-traumatic immunosuppression [12]. This model allows us to treat mice after haemorrhage and before pneumonia onset and could be reproduced when caring for trauma patients.

\section{Materials and methods}

\section{Animal care}

Experiments were conducted in accordance with the Principles of Laboratory Animal Care [13]. The committee of animal ethics of the University of Nantes approved all animal experiments in this study. Male BALB/cJ mice (20-24 g) were purchased from Janvier Laboratories (Laval, France). Mice were maintained on a 12-h light/dark cycle with free access to food and water.

\section{Haemorrhage procedure}

After general anaesthesia with isoflurane (Baxter, Maurepas, France), a transthoracic cardiac puncture was performed to withdraw one-third of the blood volaemia $(0.3 \mathrm{~mL}$ per $10 \mathrm{~g}$ body weight) [11]. The shed blood volume was restored by a retro-orbital plexus injection $90 \mathrm{~min}$ later. This volume-controlled haemorrhage has previously been shown to induce a reversible hypotension [14]. Systolic arterial pressure is normalised immediately after restitution of the shed blood volume and before pneumonia onset. The mortality induced by the cardiac puncture, if any, occurred in the first $30 \mathrm{~min}$.

\section{Pneumonia procedure}

MSSA strain (ATCC 29213, haemolysin positive and panton valentine leukocidin negative), grown for $18 \mathrm{~h}$ in tryptic soy broth medium at $37^{\circ} \mathrm{C}$, was washed twice $\left(1000 \times \mathrm{g}\right.$ for $10 \mathrm{~min}$ at $\left.37^{\circ} \mathrm{C}\right)$, diluted in sterile isotonic saline and calibrated by nephelometry. For the pneumonia procedure, transtracheal insertion of a 24 -gauge feeding needle was used to inject a lethal dose of MSSA $\left(7 \times 10^{6} \mathrm{CFU}\right)$ in anaesthetised mice (survival ranges in pneumonia group were $10-30 \%$ on day 7 ). Non-necrotising pneumonia developed in the first $24 \mathrm{~h}$ after tracheal instillation (online supplementary fig. S1; lung histological analysis).

\section{Study groups}

Mice were randomised into five groups: sham (S group), haemorrhage (H group), S. aureus pneumonia (P group), haemorrhage followed $24 \mathrm{~h}$ later by S. aureus pneumonia (HP group), and i.v. injection of 
MPLA (50 $\mu \mathrm{g}$ per animal) immediately after haemorrhage followed $24 \mathrm{~h}$ later by S. aureus pneumonia (HPMPLA group).

\section{Assessment of bacterial growth and dissemination}

Lungs and spleen were mechanically homogenised under sterile conditions. Organ homogenates were subjected to serial 10-fold dilution and plated on trypticase soy agar and selective media.

\section{Myeloperoxidase assay}

Lungs were mechanically homogenised in potassium phosphate $(50 \mathrm{mM})$ with $N$-ethylmaleimide $(10 \mathrm{mM})$. Homogenates were washed twice $\left(12000 \times g\right.$ for $30 \mathrm{~min}$ at $\left.4^{\circ} \mathrm{C}\right)$, suspended in $1 \mathrm{~mL}$ of potassium phosphate buffer $(50 \mathrm{mM})$ containing $0.5 \%$ of hexadecyl trimethylammonium, and sonicated for $180 \mathrm{~s}$. Heat shock was performed for $2 \mathrm{~h}$ at $60^{\circ} \mathrm{C}$, and samples were centrifuged at $12000 \times \mathrm{g}$ for $10 \mathrm{~min}$. The $\mathrm{H}_{2} \mathrm{O}_{2}$-dependent oxidation of $o$-dianisidine was determined by measuring absorbance at $460 \mathrm{~nm}$. Supernatant myeloperoxidase (MPO) activity was normalised to lung weight [11].

\section{Lung endothelial permeability}

Mice were given a 2-mg intraperitoneal injection of fluorescein isothiocyanate (FITC)-conjugated albumin (Sigma, Lyon, France). After $2 \mathrm{~h}$, the lungs were harvested, mechanically homogenised in isotonic saline then centrifuged $(4000 \times g$ for $10 \mathrm{~min})$. Blood was collected via right ventricular puncture and centrifuged $(4000 \times g$ for $10 \mathrm{~min})$. FITC-albumin was measured in $100-\mu \mathrm{L}$ supernatant aliquots obtained from lung homogenates and blood by fluorometry at $480 \mathrm{~nm}$. Lung endothelial permeability was calculated as previously described [11].

\section{Preparation of lung homogenate for ELISA}

Lungs samples mechanically homogenised in cold lysis buffer (PBS, 0.1\% Triton X-100) containing $1 \mathrm{mM}$ protease inhibitor cocktail (Sigma, Paris, France). Homogenates were centrifuged at $12000 \times g$ for $20 \mathrm{~min}$ at $4{ }^{\circ} \mathrm{C}$. Protein concentration in sample was determined using the BCA protein assay kit according to manufacturer's instructions (Pierce, Rockford, IL, USA). Tumour necrosis factor (TNF)- $\alpha$, IL-1 $\beta$ and macrophage inflammatory protein (MIP)-2 concentrations were quantified with ELISA kits according to manufacturer's instructions (R\&D Systems, Lille, France).

\section{Bronchoalveolar lavage}

Mice were euthanised and subjected to bronchoalveolar lavage (BAL) with $2 \mathrm{~mL}$ of sterile PBS. The BAL fluid was immediately processed for quantification of epithelial cells, DCs (CD11bCD11c lung DCs) and NK cells.

Spleen cell suspension

Spleens were digested in $2 \mathrm{mg} \cdot \mathrm{mL}^{-1}$ collagenase D (Roche Diagnostics, Meylan, France) in RPMI 1640 supplemented with $1 \%$ fetal calf serum (FCS) for $25 \mathrm{~min}$ at $37^{\circ} \mathrm{C}$. EDTA $(10 \mathrm{mM})$ was added for the last $5 \mathrm{~min}$ of digestion. The cell suspension was filtered through a $40-\mu \mathrm{m}$ filter and washed with PBS (centrifuged at $12000 \times g$ for $10 \mathrm{~min}$ at $4^{\circ} \mathrm{C}$ ).

\section{Reagents and antibodies}

MPLA was purchased from Invivogen (Toulouse, France). Monoclonal antibodies (mAb) used for cytometry and/or cell sorting were obtained from eBiosciences (San Diego, CA, USA): anti-CD3 (17A2), anti-CD8 $\alpha$ (53.6-7), anti-CD11b (M1/70), anti-CD11c (N418), anti-CD45R (B220, RA3-6B2), antiCD49beta (DX5), anti-CD69 (H1.2F3), anti-CD324 (E-cadherin, DECMA-1), anti-F4/80 (BM8), antisiglec-H (eBio440c) and anti-TLR4 (UT41). Anti-CD40 (3123), anti-CD80 (16-10A1), anti-CD86 (GL1), anti-IAd (class II major histocompatibility complex (MHC) and AMS-32.1) were obtained from BD Biosciences (Le Pont de Claix, France).

\section{Phenotypic analysis}

Splenic DCs subsets were defined by specific membrane markers: CD11c+ for cDCs and CD8 to differentiate CD8+ and CD8- cDCs; $\mathrm{B} 220$ and siglec $\mathrm{H}$ for pDCs. Lung DCs was defined as CD11c+CD11c+F4/80-. NK cells were characterised as CD3-CD49beta+CD122+ cells. DC status was assessed using the following surface markers: TLR4, CD40, CD80, CD86 and I-Ad (MHC class II), whereas CD69 was used for NK cells. Intracellular staining of TLR4 was performed after fixation and permeabilisation of the cells by Cytofix/Cytoperm Plus (BD Bioscience) according to the manufacturer's instructions. A total of $3 \times 10^{4}$ cells were analysed for maturation marker. Data were analysed using FlowJo software (Treestar, Ashland, OR, USA). 


\section{Real-time quantitative PCR}

CD8+ cDCs, CD8- cDCs and pDCs cell sorting was performed on a FACS Aria (BD Biosciences). NK cell isolation kit II (Miltenyi Biotec, Paris, France) was used according to the manufacturer's instructions for untouched NK cells selection. These procedures routinely yielded cell populations with purity up to $97 \%$ and $85 \%$, respectively. Total RNA was isolated from sorted cells with TRIzol reagent (Invitrogen, Cergy Pontoise, France) and treated for $45 \mathrm{~min}$ at $37^{\circ} \mathrm{C}$ with $2 \mathrm{U}$ of RQ1 DNase (Promega, Lyon, France). RNA $(1 \mu \mathrm{g})$ was reverse-transcribed with superscript III reverse transcriptase (Invitrogen). The cDNA $(1 \mu \mathrm{L})$ was subjected to RT-qPCR in a BioRad iCycler iQ system using the QuantiTect SYBR Green PCR kit (Qiagen, Courtaboeuf, France). Mice primer sequences for TNF- $\alpha$, IL-12p40, IL-10, IFN- $\alpha$, IFN- $\gamma$ and glyceraldehyde-3-phosphate dehydrogenase (GAPDH) are given in online supplementary table S1. GAPDH was used to normalise gene expression. Relative gene expression was calculated by the $2^{-\Delta \Delta} \mathrm{Ct}$ method using samples from the sham group as calibrator samples.

\section{Adoptive transfer of DCs and NK cells}

Spleen DCs (CD3-, CD49beta-, CD122- and CD11c+ cells) and NK cells (CD3-, CD49beta+ and CD122+ cells) were isolated from eight to 10 pooled haemorrhaged mice by cell sorting performed on a FACS Aria (BD Biosciences). Sorted spleen DCs consist of a mixture of cDCs and of pDCs (online supplementary fig. S2). Purity of isolated cell populations was $>96 \%$. DCs and NK cells were stimulated overnight with MPLA $\left(10 \mu \mathrm{g} \cdot \mathrm{mL}^{-1}\right)$, washed twice in isotonic saline solutions $(300 \times g$ for $10 \mathrm{~min})$ and intravenously administrated $\left(3 \times 10^{5}\right.$ cells per mouse).

\section{Statistical analysis}

GraphPad prism (La Jolla, CA, USA) software was used for statistical analysis. Continuous nonparametric variables were expressed as the median (interquartile range) and were compared using the Kruskal-Wallis test for multiple comparisons; the Dunn's test (post hoc test) was used for intergroup comparison and allowed us to control the family-wise type I error rate. For the adoptive transfer experiments, survival curves were compared with a log-rank test. Bonferroni's correction was used for multiple comparisons. A p-value $<0.05$ was considered to be statistically significant.

\section{Results}

MPLA decreased MSSA systemic dissemination and lung inflammatory lesions

In mice undergoing post-haemorrhage pneumonia, MPLA was found to decrease MSSA systemic dissemination and lung inflammatory lesions. The mortality was previously reported to be higher in the HP group (mice undergoing post-haemorrhage pneumonia) than in the P group and in treated mice (HPMPLA group) [11]. We first assessed whether MPLA injection alters lung response to post-haemorrhage pneumonia. Lungs and spleen were harvested $24 \mathrm{~h}$ after $S$. aureus intratracheal instillation. Haemorrhage did not modify the bacterial load in the lungs (fig. 1a), but increased the systemic dissemination of MSSA (fig. 1b). Haemorrhage compounded the pneumonia-induced neutrophil accumulation, the pneumoniainduced lung endothelial lesions and increased IL-1 $\beta$ production (fig. 1b-e). MPLA treatment (HP-MPLA group) significantly decreased the spleen bacterial load, the MPO activity and lung endothelial lesions without altering the production of pro-inflammatory cytokines in the lungs compared with mice left untreated (HP group) (fig. 1b-g). Pneumonia increased the BAL proportions of lung DCs and NK cells (fig. 1h and i). Neither haemorrhage nor MPLA altered the pneumonia-induced DC and NK cell accumulation.

\section{MPLA partially restores TNF- $\alpha$, IFN- $\alpha$ and IL-12 mRNA levels in splenic DCs}

In mice undergoing post-haemorrhage pneumonia, MPLA partially restores TNF- $\alpha$, IFN- $\alpha$ and IL-12 mRNA levels in splenic DCs. Lung inflammation and phagocyte recruitment are modulated by cDCs and pDCs in murine models of sepsis [15] or haemorrhage [16]. Three main subsets of splenic DCs have been described in mice: CD8+ cDCs orientate the adaptive immune response toward an inflammatory response and produce large amounts of IL-12; CD8- cDCs exhibit an anti-inflammatory action through IL-10 production; and pDCs are specialised in IFN- $\alpha$ secretion [4]. We previously showed that haemorrhage alters cytokine production and co-stimulatory molecule expression in splenic DCs after pneumonia [11]. We thus investigated whether MPLA restores the transcription of cytokines in splenic DCs within post-haemorrhage pneumonia. Spleens were harvested $6 \mathrm{~h}$ after S.aureus tracheal instillation (online supplementary fig. S3). In CD8+ cDCs (fig. 2a-c), MPLA treatment (HP-MPLA group) partially restored TNF- $\alpha$ and restored IL-12p40 mRNA level compared with mice left untreated (HP group). MPLA increased the IFN- $\alpha$ mRNA expression compared with all other groups. In CD8- cDCs (fig. $2 \mathrm{~d}-\mathrm{f}$ ), TNF- $\alpha$, IL-10 and IFN- $\alpha$ mRNA expressions were not altered by MPLA treatment (HP-MPLA group) compared with post-haemorrhage pneumonia (HP group). In pDCs (fig. $2 \mathrm{~g}$ and h), MPLA treatment did not alter TNF- $\alpha$ expression but partially restored IFN- $\alpha$ compared with post-haemorrhage infected mice left untreated (HP group). 

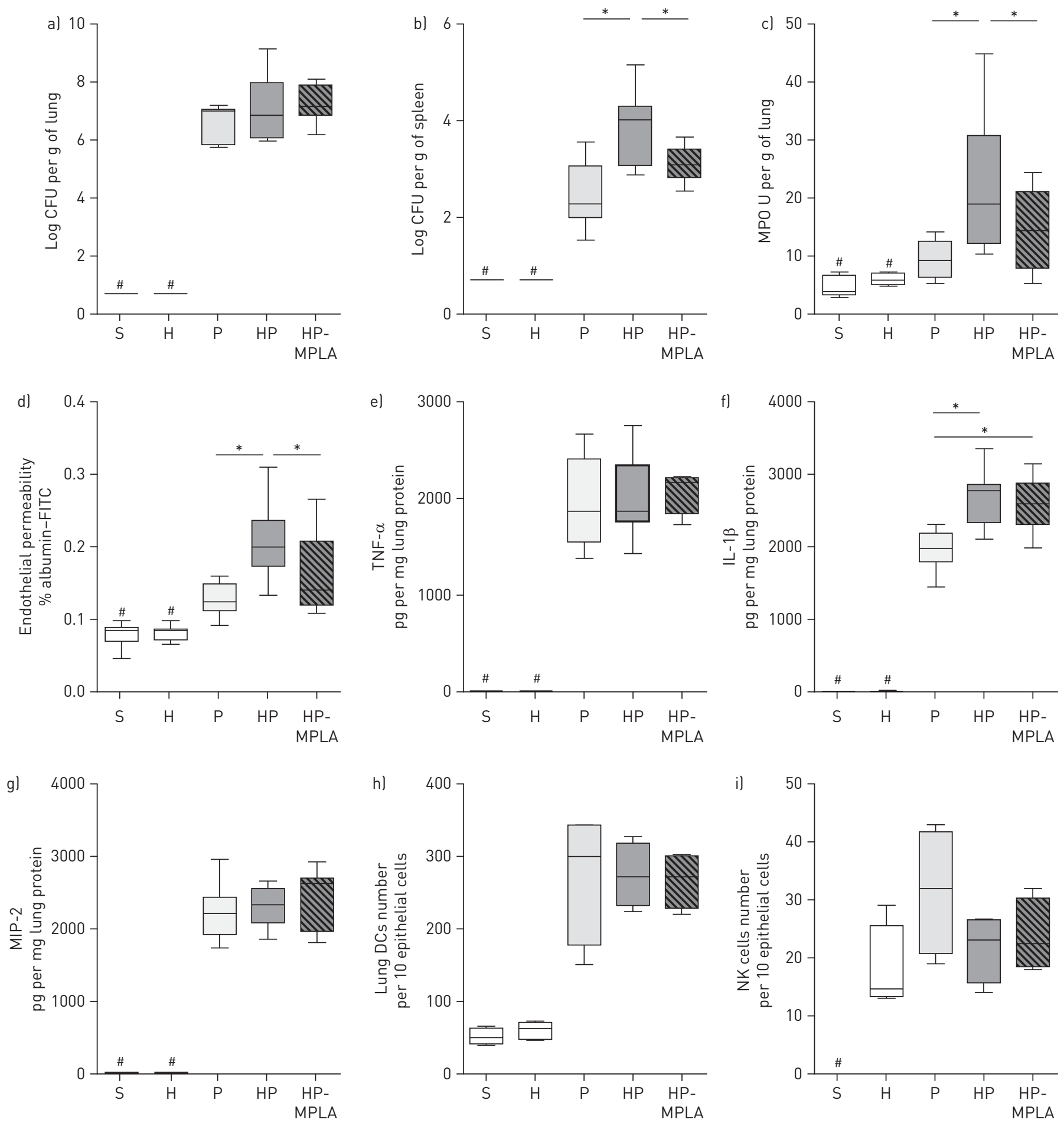

FIGURE 1 Monophosphoryl lipid A (MPLA) decreased Staphylococcus aureus systemic dissemination and lung inflammatory lesions in mice undergoing posthaemorrhage pneumonia. Five groups of mice were studied: sham (S), haemorrhage alone (H), S. aureus pneumonia alone (P), post-haemorrhage S. aureus pneumonia (HP) and MPLA-treated mice undergoing post-haemorrhage S. aureus pneumonia (HP-MPLA). Lungs and spleen were harvested $24 \mathrm{~h}$ after tracheal instillation. Local and systemic bacterial burden were assessed in a) the lungs and b) the spleen with a lower detection limit for this method being 1 CFU per $50 \mu \mathrm{L}$ of undiluted tissue homogenate. c) Neutrophil accumulation was assessed by measurement of myeloperoxydase activity (MPO) and d) endothelial permeability was measured using albumin-fluorescein isothiocyanate (FITC). Concentrations of e) tumour necrosis factor (TNF)- $\alpha, f)$ interleukin (IL)- $1 \beta$ and g) macrophage inflammatory protein (MIP)-2 were assessed in lung homogenates. The proportions of h) lung dendritic cells (DCs) and i) natural killer (NK) cells were assessed in bronchoalveolar lavage. Data are presented as median (interquartile range), which issue from two independent experiments ( $\mathrm{n} \geqslant 5$ mice per group). ${ }^{*}: \mathrm{p}<0.05$ compared with P, HP and HP-MPLA groups; ${ }^{*}: \mathrm{p}<0.05$. 

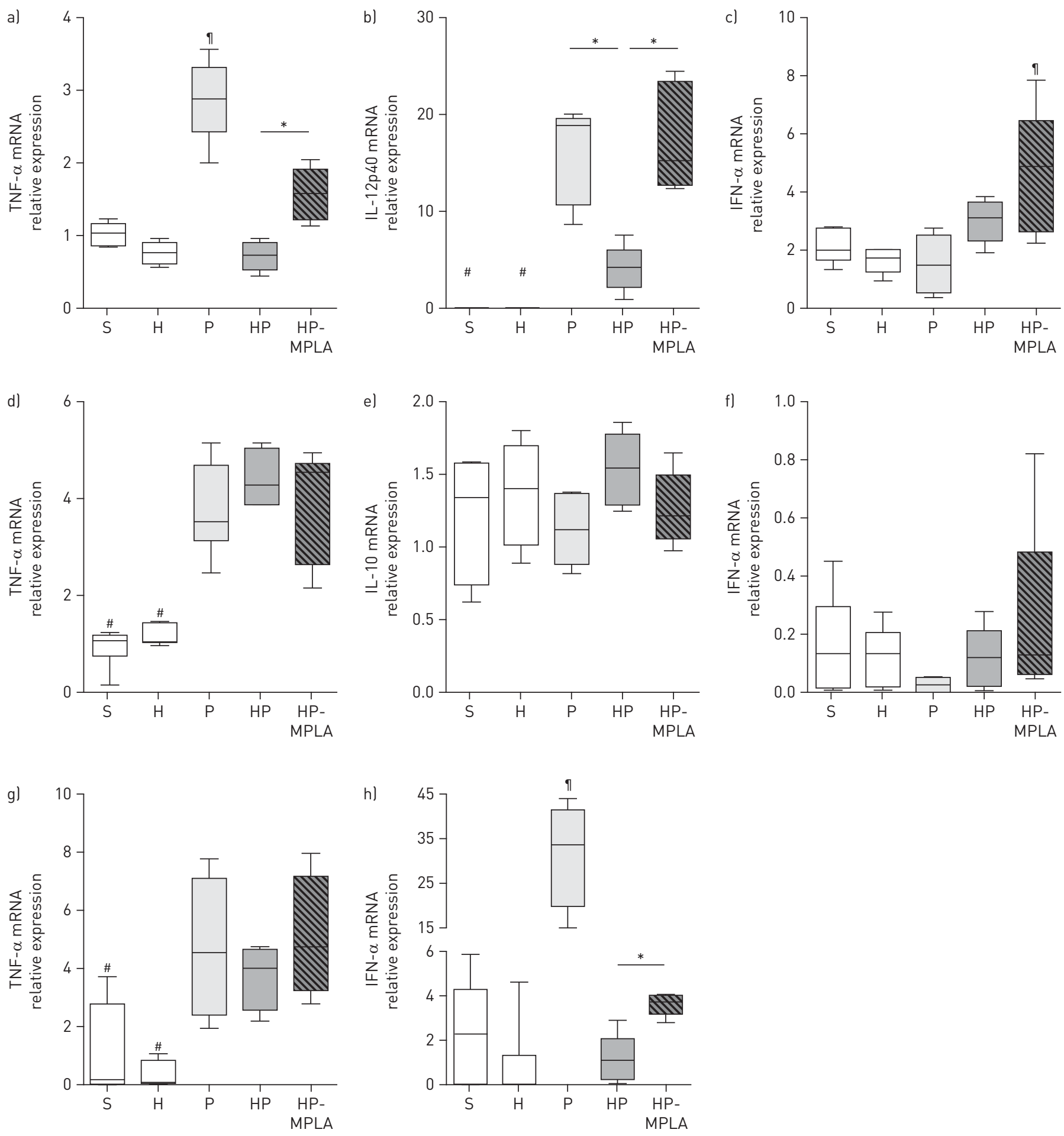

FIGURE 2 Monophosphoryl lipid A (MPLA) partially restores tumour necrosis factor (TNF)- $\alpha$, interleukin (IL)-12 and interferon (IFN)- $\alpha$ mRNA levels in dendritic cells (DCs) in mice undergoing post-haemorrhage Staphylococcus aureus pneumonia. Five groups of mice were studied: sham (S), haemorrhage (H), S. aureus pneumonia (P), post-haemorrhage S. aureus pneumonia (HP) and MPLA-treated mice undergoing post-haemorrhage S. aureus pneumonia (HPMPLA). Spleens were harvested $6 \mathrm{~h}$ after tracheal instillation. mRNA levels of a) TNF- $\alpha, \mathrm{b}$ ) IL-12p40 and c) IFN- $\alpha$ were assessed in CD8+ conventional DCs (cDCs); d) TNF- $\alpha$, e) IL-10 and f) IFN- $\alpha$ were assessed in CD8- cDCs; and g) TNF- $\alpha$ and h) IFN- $\alpha$ were assessed in plasmacytoid DCs. Data are presented as median (interquartile range), which issue from two independent experiments ( $\mathrm{n} \geqslant 6$ mice per group). ${ }^{*}: \mathrm{p}<0.05$ compared with P, HP and HP-MPLA groups; ${ }^{\bullet}: \mathrm{p}<0.05$ versus all others; ${ }^{*}: \mathrm{p}<0.05$. 

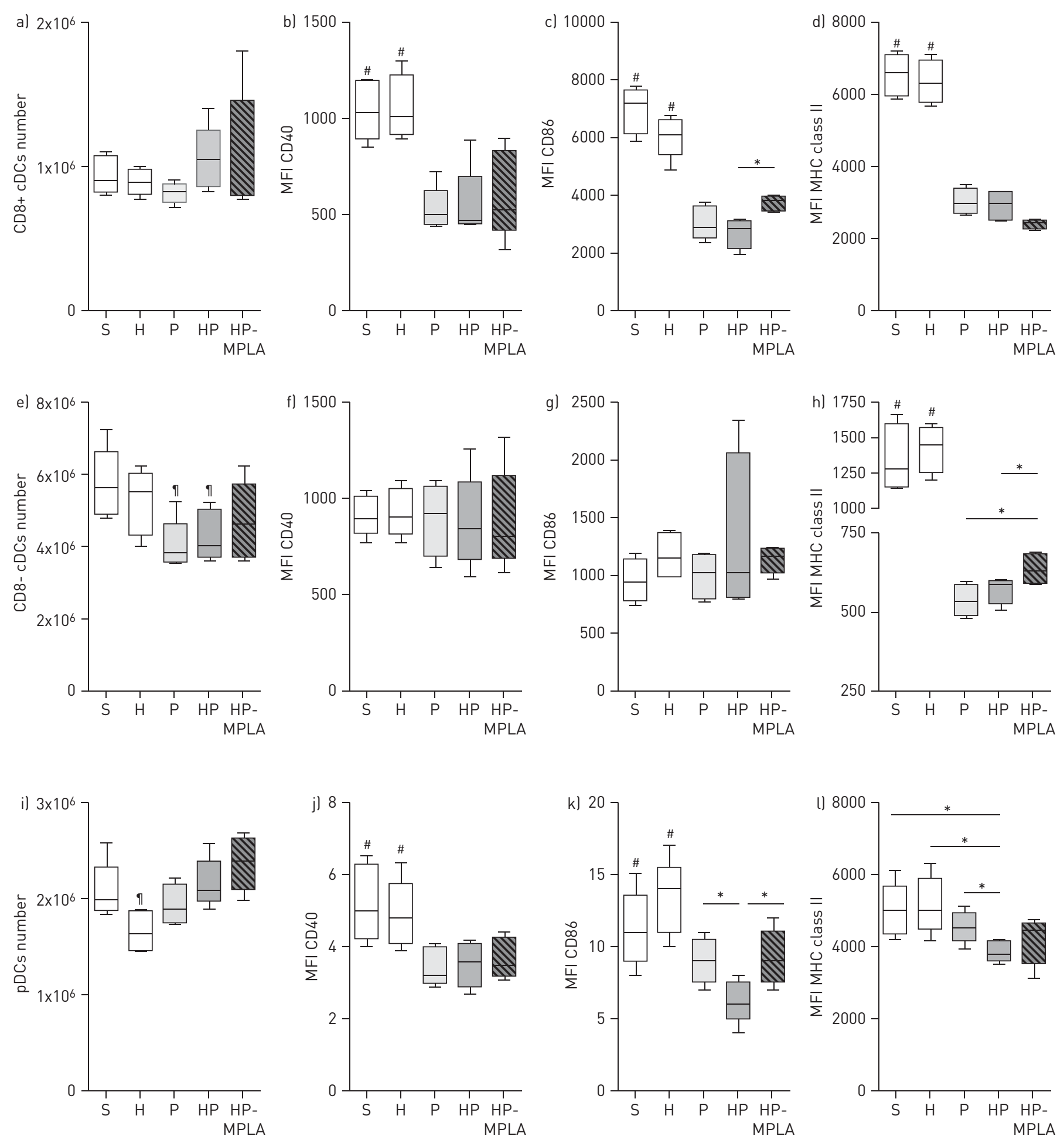

FIGURE 3 Monophosphoryl lipid A (MPLA) altered the maturation status of myeloid and plasmacytoid dendritic cells (DCs) in mice undergoing posthaemorrhage Staphylococcus aureus pneumonia. Five groups of mice were studied: sham (S), haemorrhage alone (H), S. aureus pneumonia alone (P), posthaemorrhage S. aureus pneumonia (HP) and MPLA-treated mice undergoing post-haemorrhage S. aureus pneumonia (HP-MPLA). Mice were sacrificed 6 h after tracheal instillation. Cell numbers and maturation markers (CD40, CD86 and major histocompatibility complex (MHC) class II) were assessed in splenic a-d) CD8+ conventional DCs (cDCs), e-h) CD8- cDCs and i-l) plasmacytoid DCs (pDCs). Data are presented as median (interquartile range), which issue from two independent experiments ( $\mathrm{n} \geqslant 6$ mice per group). MFI : mean fluorescence intensity. ${ }^{\#}: \mathrm{p}<0.05$ compared with $\mathrm{P}, \mathrm{HP}$ and HP-MPLA groups; ${ }^{\circ}: \mathrm{p}<0.05$ versus all others; ${ }^{*}: \mathrm{p}<0.05$. 


\section{MPLA partially restores the maturation status of conventional and plasmacytoid DCS}

In mice undergoing post-haemorrhage pneumonia, MPLA partially restores the maturation status of conventional and plasmacytoid DCs. MPLA restored the expression of TNF- $\alpha$ and IFN- $\alpha$ and may, therefore, accelerate the maturation of DCs. To gain further knowledge, we assessed the effect of MPLA on the membrane expression of maturation markers (CD40, CD86 and MHC class II) in DCs. It is noteworthy that MPLA treatment did not modify the number of spleen DC subsets compared with mice left untreated (HP group, fig. 3a-1). In CD8+ cDCs, MPLA treatment increased CD86 expression and had no effect on expression of CD40 and MHC class II compared with mice left untreated (HP group) (fig. 3a-d). In CD8cDCs, MPLA treatment increased MHC class II expression and had no effect on expression of CD40 and CD86 (fig. 3e-h). In pDCs, MPLA treatment (HP-MPLA group) increased CD86 expression but not CD40 and MHC class II expression compared with mice left untreated (HP group) (fig. 3i-l).

\section{MPLA prevented IL-10 mRNA overexpression in NK cells}

In mice undergoing post-haemorrhage pneumonia, MPLA prevented IL-10 mRNA overexpression in NK cells. NK cell-to-DC cross-talk is critically involved in the maturation of DCs during bacterial infection [7, 10]. We thus investigated the functional status of NK cells and whether MPLA alters the NK cells' response to infection in haemorrhaged mice. Spleens were harvested $24 \mathrm{~h}$ after S. aureus tracheal instillation (online supplementary fig. S3). The number of splenic NK cells was decreased in mice undergoing posthaemorrhage pneumonia (HP group) compared with infected mice (P group), without any effect of MPLA (HP-MPLA group, fig. 4a). NK cells exhibited a more activated phenotype in HP group compared with $\mathrm{P}$ group as shown by surface CD69 expression (fig. 4b). MPLA treatment did not modify the percentage of $\mathrm{CD} 69^{+} \mathrm{NK}$ cells compared with mice left untreated (HP group, fig. 4b). IFN- $\gamma$, which is mainly produced by NK cells [5], is critically involved in the defence of the host against pathogens. IFN- $\gamma$ mRNA expression was strongly decreased in mice undergoing post-haemorrhage pneumonia compared with pneumonia alone (P group), and was not restored by MPLA treatment (HP-MPLA group, fig. 4c). IL-10 is the main antiinflammatory cytokine described to date in the haemorrhage-induced immunosupression [17]. In this setting, the main cellular source of this cytokine remains controversial. We found that IL-10 mRNA level in NK cells was dramatically increased in the HP group compared with the P group and that MPLA treatment decreased IL-10 mRNA levels compared with the HP group (fig. 4d).

\section{MPLA-stimulated DCs increase survival in mice undergoing post-haemorrhage pneumonia}

We aimed to determine which cells directly respond to MPLA. We therefore assessed the expression of TLR4 in DCs and NK cells. pDCs have a restrictive TLR repertory without TLR4 expression [4]. The membrane expression of TLR4 in cDCs was not altered in our experiments (fig. $5 \mathrm{a}$ and b). As previously described in NK cells [18], we failed to detect surface expression of TLR4 on NK cells (data not shown), but intracellular TLR4 levels were decreased in the H and HP groups compared with the control (group S, fig. 5c). Despite this decreased TLR4 expression in NK cells, MPLA improved the function of both DCs and NK cells in vivo. We thus evaluated if the effect of MPLA was restricted to a direct stimulation of each cellular type or to a cross-talk between these cells. To address this issue, splenic DCs and NK cells were harvested from haemorrhaged mice (fig. 6a). Figures $6 \mathrm{~b}-\mathrm{d}$ are representative of the cells' sorting strategy for splenic DCs and NK. DCs and NK cells were cultured overnight ex vivo either with or without MPLA $\left(10 \mu \mathrm{g} \cdot \mathrm{mL}^{-1}\right)$. Cells were cultured either separately or together before being i.v. administered to haemorrhaged mice concomitantly to MSSA tracheal instillation (fig. 6a). The survival rates were assessed over $168 \mathrm{~h}$. Compared with the HP group, the survival rate increased from $8 \%$ to $31 \%$ in haemorrhaged mice recipient of MPLA-stimulated DCs (HP-stimulated DCs group; $\mathrm{p}=0.03$ ) and to $42 \%$ in haemorrhaged mice recipient of MPLA-stimulated DCs/NK cells cultured together (HP-stimulated DCs/NK group; $\mathrm{p}=0.02$ versus $\mathrm{HP}$ group) (fig. 6e). Neither the adoptive transfer of unstimulated cells nor the administration of MPLA-stimulated NK cells (HP-stimulated NK group) altered the survival rate (fig. 6e). All together, these results suggest that a direct MPLA-stimulation of DCs is involved in the protective effect of MPLA treatment, whereas the direct TLR4 stimulation of NK cells appears dispensable in this model.

\section{NK cells are required for the protective effect of MPLA in post-haemorrhage pneumonia}

To investigate whether NK cells are dispensable for the protective effect of MPLA in vivo, we assessed the impact of NK cells depletion during post-haemorrhage pneumonia. NK cell depletion, was performed through an i.v. injection of anti-asialo GM1 (anti-ASGM1) $(25 \mu \mathrm{L}$; Wako Pure Chemicals, Osaka, Japan) $24 \mathrm{~h}$ before haemorrhage procedure (fig. 7a). We next assessed the survival rate of MPLA-treated haemorrhaged mice with or without NK cells depletion. The survival rate decreased from 40\% in MPLAtreated haemorrhaged mice (HP-MPLA group) to $0 \%$ in mice depleted in NK cells (HP (depleted NK)MPLA group; $\mathrm{p}=0.03$ ) (fig. 7b). These results underline the critical role of NK cells in the immune response 

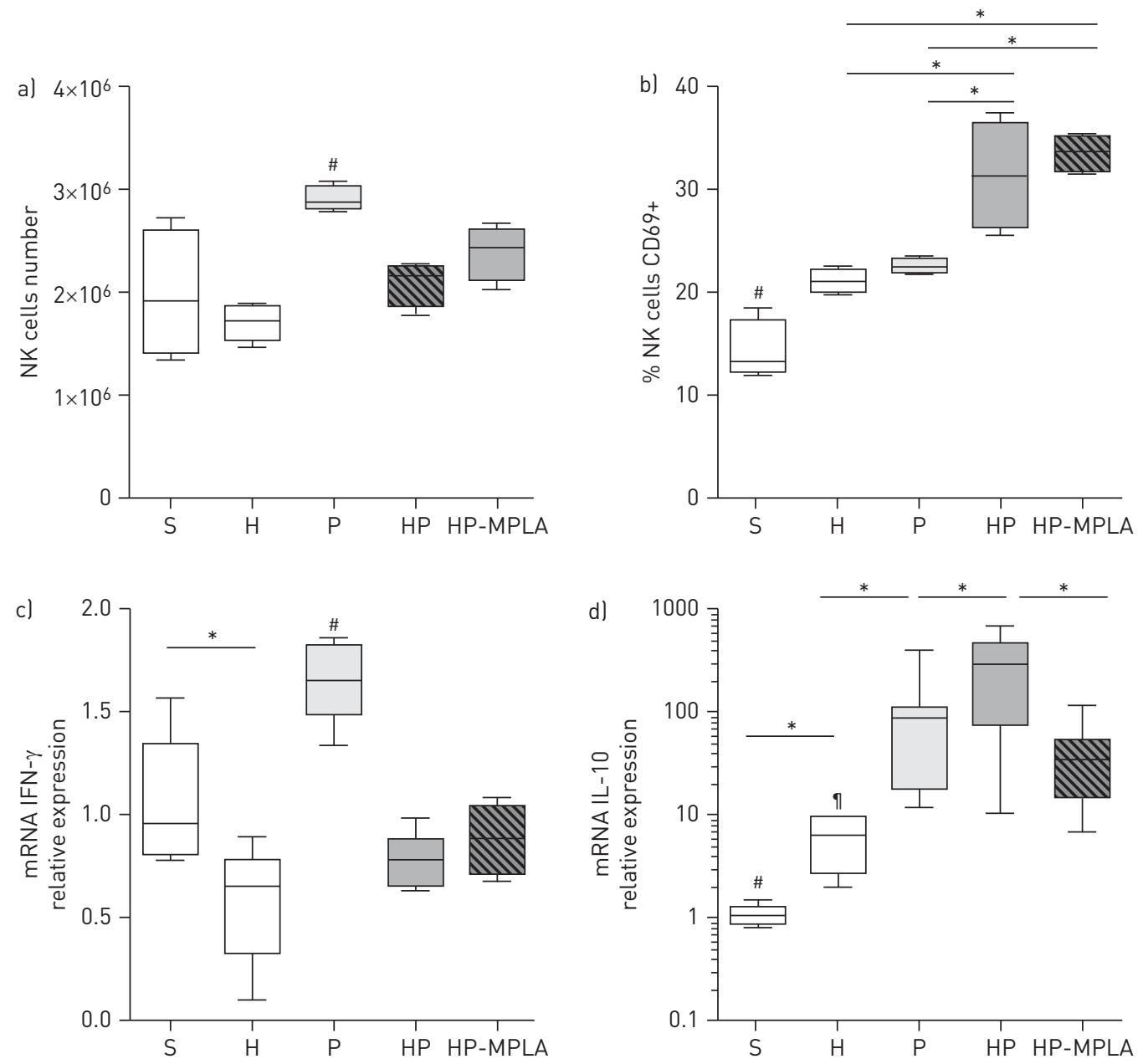

FIGURE 4 Monophosphoryl lipid A (MPLA) decreased interleukin (IL)-10 mRNA level in natural killer (NK) cells of mice undergoing post-haemorrhage Staphylococcus aureus pneumonia. Five groups of mice were studied: sham (S), haemorrhage $(\mathrm{H})$, S. aureus pneumonia $(\mathrm{P})$, post-haemorrhage S. aureus pneumonia (HP) and MPLA-treated mice undergoing posthaemorrhage $S$. aureus pneumonia (HP-MPLA). Spleens were harvested $24 \mathrm{~h}$ after tracheal instillation. a) NK cell numbers, b) percentage of CD69+ cells and mRNA levels of c) interferon (IFN) $-\gamma$ and d) IL-10 were assessed in splenic NK cells. Data are presented as median (interquartile range), which issue from two independent experiments ( $n \geqslant 6$ mice per group). ${ }^{\#}: \mathrm{p}<0.05$ compared with all other groups; ${ }^{\circ}: \mathrm{p}<0.05$ compared with infected groups; ${ }^{*}: \mathrm{p}<0.05$.

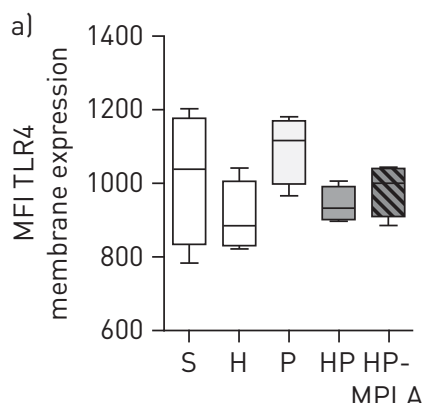

MPLA
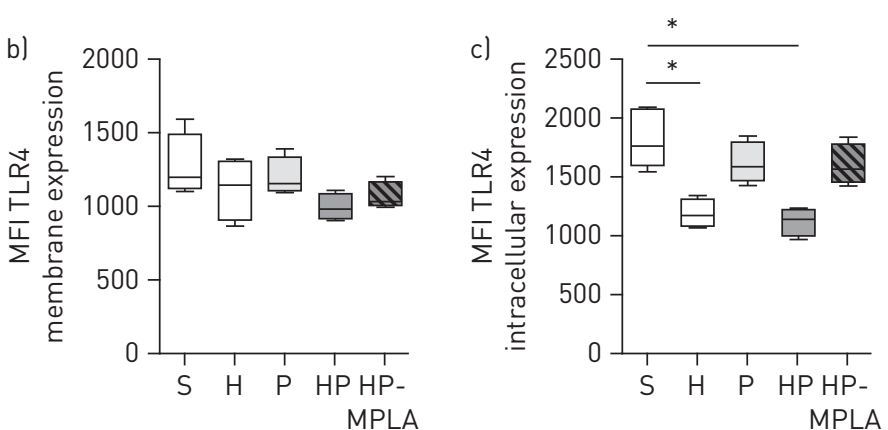

FIGURE 5 Toll-like receptor (TLR)4 membrane expression was unchanged in conventional dendritic cells (cDCs), but intracellular expression was decreased in natural killer (NK) cells from mice with haemorrhage $(\mathrm{H})$ or post-haemorrhage Staphylococcus aureus pneumonia (HP). Five groups of mice were studied: sham (S), H alone, S. aureus pneumonia alone (P), HP and monophosphoryl lipid A (MPLA)-treated mice with HP. TLR4 levels were assessed on membranes of a) CD8+ cDCs and b) CD8- cDCs, and c) intracellular TLR4 levels were assessed in NK cells. MFI: mean fluorescence intensity. ${ }^{*}: \mathrm{p}<0.05$ versus $\mathrm{S}$ group. 


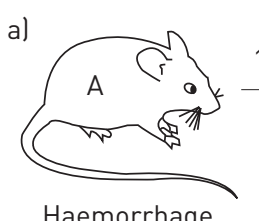

$12 \mathrm{~h}$

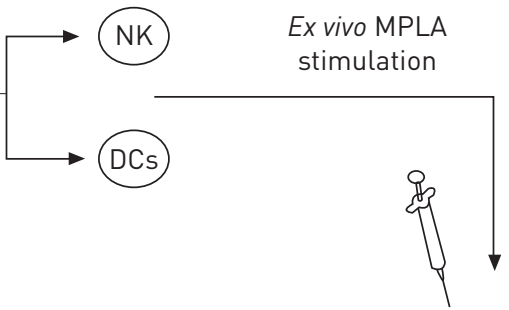

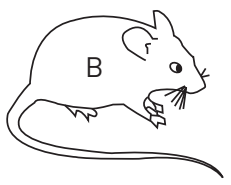

Haemorrhage
$24 \mathrm{~h}$

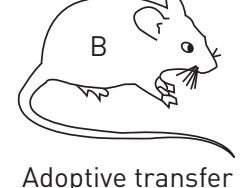

+pneumonia b)

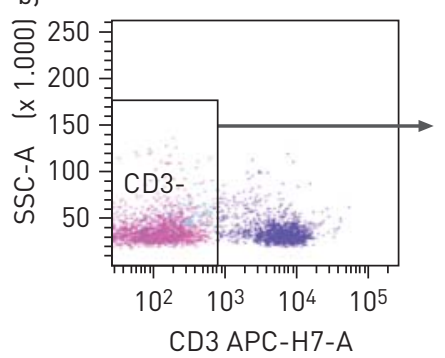

c)

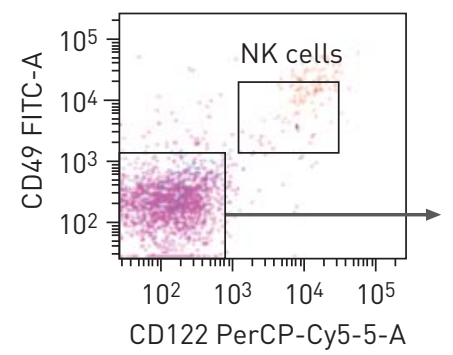

Survival

rate
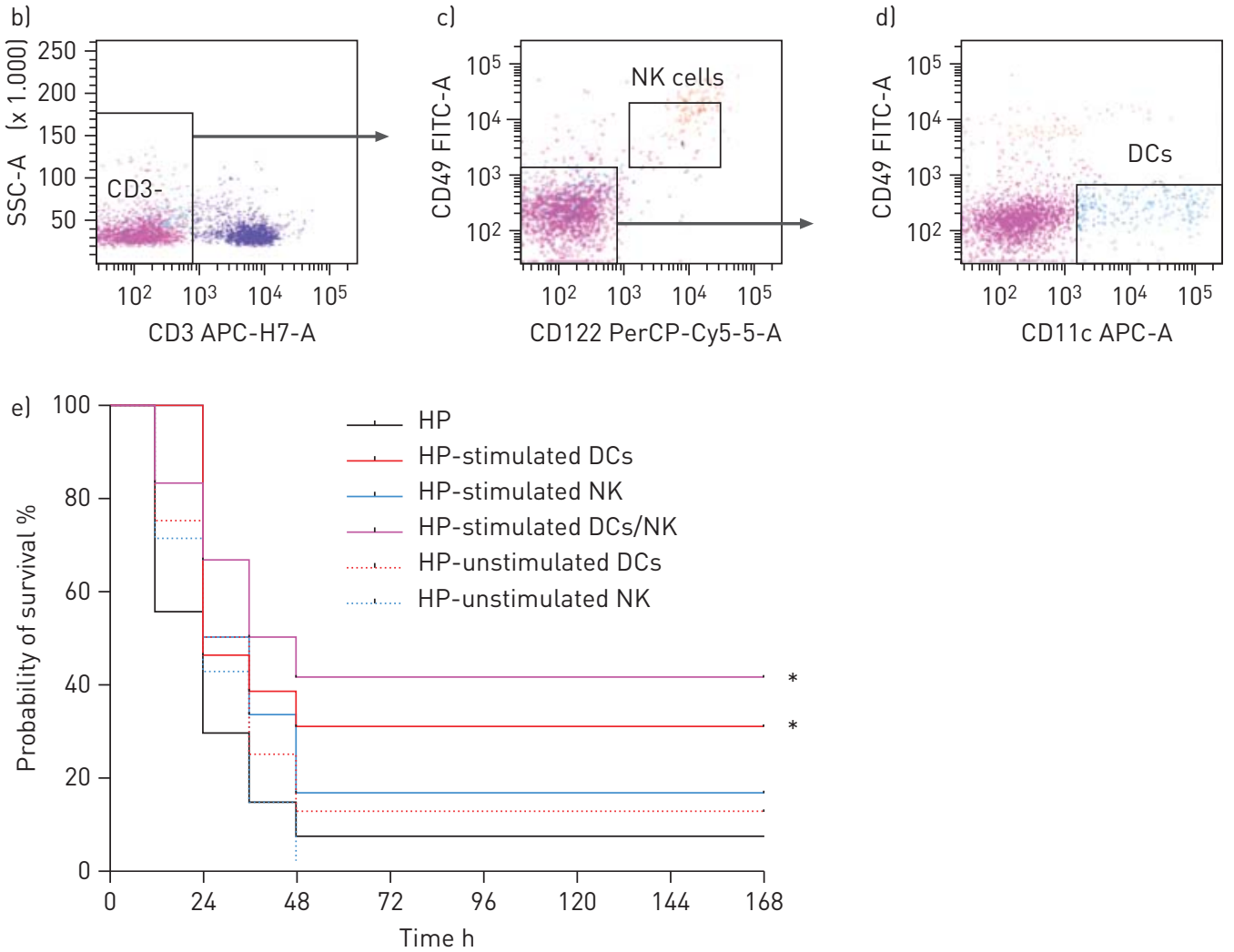

FIGURE 6 Monophosphoryl lipid A (MPLA)-stimulated dendritic cells (DCs) increased the survival rate of mice undergoing post-haemorrhage pneumonia. a) Schematic of experiment. Mice spleens were harvested $12 \mathrm{~h}$ after haemorrhage. Splenic natural killer (NK) cells (CD3-, CD49 + and CD122+ cells) and DCs (CD3-, CD49 $\beta$ - and CD11c+ cells) were sorted $(\mathrm{b}-\mathrm{d})$ and then cultured with or without MPLA $\left(10 \mu \mathrm{g} \cdot \mathrm{mL}^{-1}\right)$ overnight. Stimulated and unstimulated cells $\left(3 \times 10^{5}\right.$ cells per mouse) were i.v. administered to haemorrhaged mice that concomitantly received intratracheal instillation of Staphylococcus aureus. e) The survival rates of six groups were assessed over 168 h: post-haemorrhage pneumonia without adoptive transfer (HP group; $n=18$ ), haemorrhaged mice receiving unstimulated DCs (HP-unstimulated DCs group; $\mathrm{n}=8$ ); unstimulated NK cells (HP-unstimulated NK group; $\mathrm{n}=8$ ); MPLA-stimulated DCs (HP-stimulated DCs group; $\mathrm{n}=13$ ); MPLA-stimulated NK cells (HP-stimulated NK group; $\mathrm{n}=12$ ); MPLAstimulated DCs/NK cells co-culture (HP-stimulated DCs/NK group; $\mathrm{n}=12$ ). Survival rates are expressed as percentage and are representative of two independent experiments. SSC-A: side-scatter analogue; FITC: fluorescein isothiocyanate. ${ }^{*} \mathrm{p}<0.05$ versus $\mathrm{HP}$ group.

to pneumonia and suggest that NK cells participate to the protective effect of MPLA in this model of haemorrhage-induced immune dysfunction.

\section{Discussion}

The effects of MPLA during post-haemorrhage pneumonia can be summarised as follows: 1) MPLA decreases both systemic dissemination of $S$. aureus and lung lesions; 2) MPLA partially restores DC 
a)

NK cell

depletion

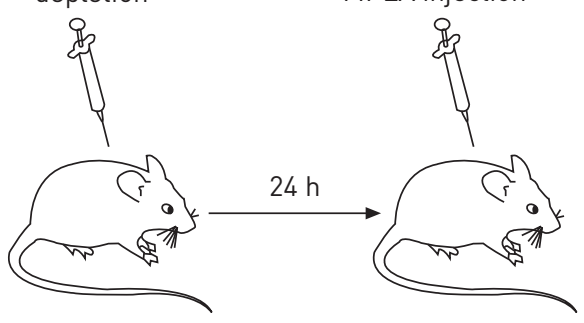

Haemorrhage

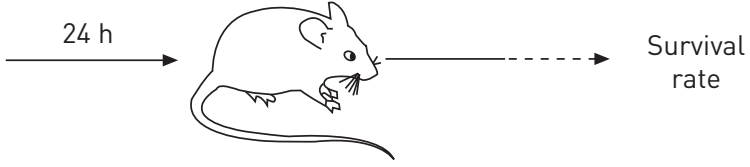

Pneumonia

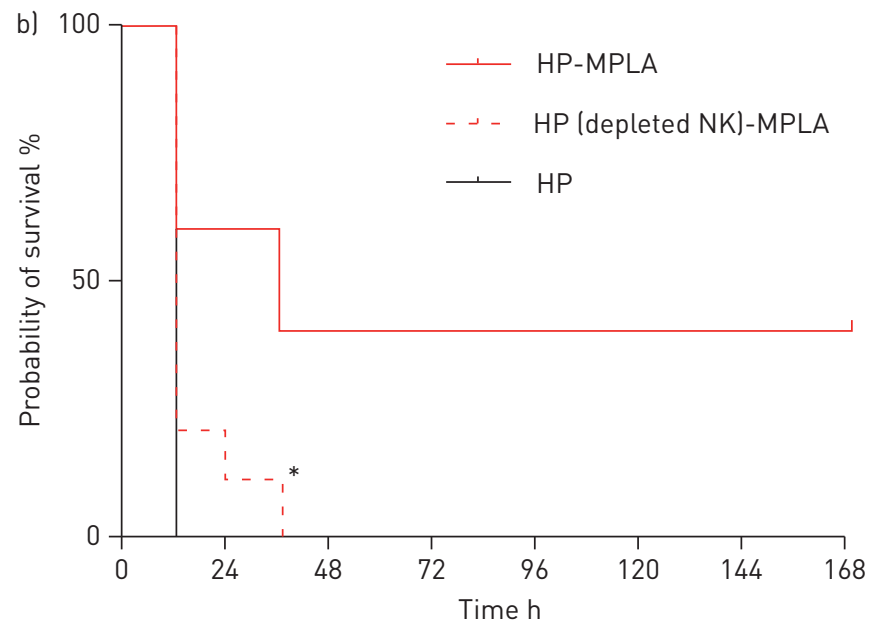

FIGURE 7 The depletion of natural killer (NK) cells decreased the survival rate of monophosphoryl lipid A (MPLA)treated mice undergoing post-haemorrhage Staphylococcus aureus pneumonia. a) For NK cell depletion, mice were given an i.v. injection of anti-asialo GM1 (25 $\mu \mathrm{L}$ per mouse) $24 \mathrm{~h}$ before haemorrhagic shock. MPLA was i.v. injected immediately after haemorrhage and followed $24 \mathrm{~h}$ later by tracheal instillation of $S$. aureus. b) We assessed the survival rates of mice undergoing post-haemorrhaged methicillin-sensitive $S$. aureus pneumonia (HP group; $\mathrm{n}=10$ ), of haemorrhaged mice treated with MPLA (HP-MPLA group; $\mathrm{n}=10$ ) or of haemorrhaged mice treated with MPLA after depletion in NK cells (HP (depleted NK)-MPLA group; $n=10$ ). Data are expressed as percentages and are representative of two independent experiments. ${ }^{*}: \mathrm{p}<0.05$ versus HP-MPLA group.

functions and prevents IL-10 mRNA overexpression in NK cells; and 3) a direct MPLA-activation of DCs decreases mortality, whereas NK cells are not dispensable to immune response to pneumonia.

Murine models of haemorrhagic shock are frequently used for the study of trauma-induced immunosuppression because they reproduce its main features: a decreased cytokine production by circulating leukocytes after TLR stimulation [14], a decreased HLA-DR expression on antigen-presenting cells [12] and alteration in adaptive immune response [19]. Among the different murine haemorrhage models, Wiggers' model [20] consists of an irreversible shock inducing prolonged hypotension. However, the common cause of death in human trauma patients is rapid exsanguination and not protracted hypotension. In the present model with resuscitation, awake mice may limit hypotension through a hormonal response, which is a major determinant of the immune response to infection. Moreover, cardiac puncture directly alters the immune response [14], more faithfully reproducing the clinical scenario of trauma-induced haemorrhage than haemorrhage without tissue damage. Post-traumatic pneumonia (the model of infection), which affects up to $40 \%$ of patients, is mainly induced by MSSA [2]. Thus, the current model of post-haemorrhage $S$. aureus pneumonia closely mimics the clinical situation and appears to be useful for pre-clinical evaluation of immunomodulation treatment after trauma.

DCs are closely associated with the respiratory epithelium and extend processes into the lumen of the airway. These extensions enable the activation of DCs by bacteria through the recognition of pathogenassociated molecular pattern using pattern-recognition receptors. Stimulated DCs produce cytokines and chemokines that regulate the influx of phagocytes and enhance lung bacterial clearance. Matured DCs migrate into lymphoid tissues and present antigen to the lymphocytes. Adaptive immune cells are recruited after several days; they reduce the systemic bacterial burden through antibody production and complement cascade activation [21]. We have reported that haemorrhage did not alter the lung bacterial clearance 
(phagocyte cells), but increased spleen bacterial burden (adaptive immune response). This paradox was also described in a murine model of sepsis-induced immune dysfunction [15]. Several hypotheses could explain this discrepancy between local and systemic bacterial clearance. First, in a murine model of Toxoplasma gondii infection, NK cells engaged in an IL-10-mediated immunoregulatory circuit reduced systemic inflammation but increased dissemination of the pathogen [22]. In the current model, haemorrhage induced a blunting of IL-10 transcription in NK cells that could increase the systemic dissemination of S. aureus. Secondly, a decreased bacterial antigen-specific pulmonary B-cell function [19] or cytotoxic T-cell function [21] could participate in bacterial dissemination after trauma. Finally, the systemic evolution of post-haemorrhage $S$. aureus pneumonia underlines the critical importance of an adequate coordination of innate and adaptive immune responses.

To efficiently fight against infection, matured DCs activate adaptive immunity through membrane expression of two families of molecules: the first one is composed of the MHC class II molecules (HLA-DR in humans) and the second one is composed of co-stimulatory molecules (CD80 and CD86 molecules). Presentation of antigens without co-stimulatory molecules leads to tolerance through T-cell anergy or apoptosis. In this setting, inflammatory processes, such as haemorrhage or pneumonia, alter the capacity for antigen presentation of DCs [23], and the decreased HLA-DR (MHC class II) expression on monocytes and DCs is one of the most described features of the post-traumatic immunosuppression in humans. Type I IFNs have emerged as central coordinators of innate and adaptive immune response as they induce maturation of antigen-presenting cells and are involved in lung response to extracellular bacteria. TLR4 recruits two different Toll/interleukin-1 receptor-domain-containing adaptors: first, TLR4/MyD88 pathway activates the transcription factor nuclear factor $(\mathrm{NF})-\kappa \mathrm{B}$ and the transcription of pro-inflammatory cytokines; secondly, the TLR4/TRIF pathway leads to phosphorylation of the transcription factor interferon regulatory factor (IRF)3, leading to the transcription of type I IFN [24]. A weak nuclear translocation of NF- $\kappa B$, in response to an ex vivo activation of the TLR4/MyD88 pathway by lipopolysaccharide, has been reported in circulating mononuclear cells of trauma patients [25]. To date, the functionality of the TLR4/TRIF pathway after trauma-haemorrhage has not been documented. Interestingly, the recruitment of TRIF on TLR4 activation is involved in lung circumscription of bacteria during pneumonia [26]. In the present model of haemorrhage-induced immune dysfunction, MPLA, a TRIF-biased TLR4 agonist [27], increases the transcription of both IRF- (IFN- $\alpha$ ) and NF- $\mathrm{KB}$ (TNF- $\alpha$ and IL-12p40)-dependent cytokines in DCs.

The cluster of matured DCs with NK cells is critical for initiating T-cell-mediated immune response within bacterial infection [28]. Two subsets of NK cells are described so far: 1) IFN- $\gamma$ secreting NK cells (NK1) exhibit a cytotoxic activity that enables the destruction of infected cells; and 2) IL-10 secreting NK cells (NK2) display regulatory functions through an inhibition of antigen-induced T-cell proliferation [29]. Alterations of NK cells were described in trauma patients and were associated with pneumonia after brain injury in mice [6]. The ability of MPLA to decrease the IL-10 production in this mouse model may prove important, as IL-10 was constantly demonstrated to be a key factor regarding post-traumatic immunosuppression. In critically ill patients, IL-10 is responsible for monocytic deactivation in braininjured patients [30]. In injured patients, IL-10 production and HLA-DR suppression precede nosocomial pneumonia [31]. The shift from IFN- $\gamma$ to IL-10 transcription in NK cells may thus contribute to the decreased DCs maturation during post-haemorrhage pneumonia.

The cross-talk between DCs and NK cells is critical for the maturation of the both cell lineages during bacterial infection. The maturation of DCs toward pro-inflammatory or tolerogenic characteristics depends on a direct TLR4 activation and on the integration of cell-to-cell contact with IFN- $\gamma$ secreting NK cells [10]. NK cell activation requires cytokines (such as IL-12 and IFN- $\alpha$ ), and cell contact with activated DCs [28]. Accordingly, we reported that the protective effect of MPLA requires the action of both DCs and NK cells to restore immune homeostasis in haemorrhaged mice. Interestingly, the direct TLR4 stimulation of NK cells did not improve mortality in our model. These data are in line with two recent studies showing that NK cell reactivity to TLR4 agonist, was reduced in a murine model of sepsis-induced immunosuppression [18] and in humans suffering from sepsis or sterile systemic inflammation [32]. Finally, NK cell hyporeactivity to MPLA could be related to haemorrhage-induced decrease in intracellular TLR4.

Our study has several limitations. First, we used a murine model that limits the extrapolation of the results to humans. However, this model reproduces the main immunological features of the post-traumatic immunosuppression reported in humans and S. aureus pneumonia is the most frequent complication in trauma patients. Secondly, we reported that both DCs and NK cells express TLR4, but we did not demonstrate that MPLA is specific to this receptor. Adoptive transfer of ex vivo stimulated cells has demonstrated that DCs are directly altered by MPLA, but despite the fact that ex vivo treated NK cells did not alter survival, we cannot exclude that NK cells were responsive to MPLA. Finally, other cells, such as alveolar macrophages, could also be involved in trauma-induced immunosuppression. 

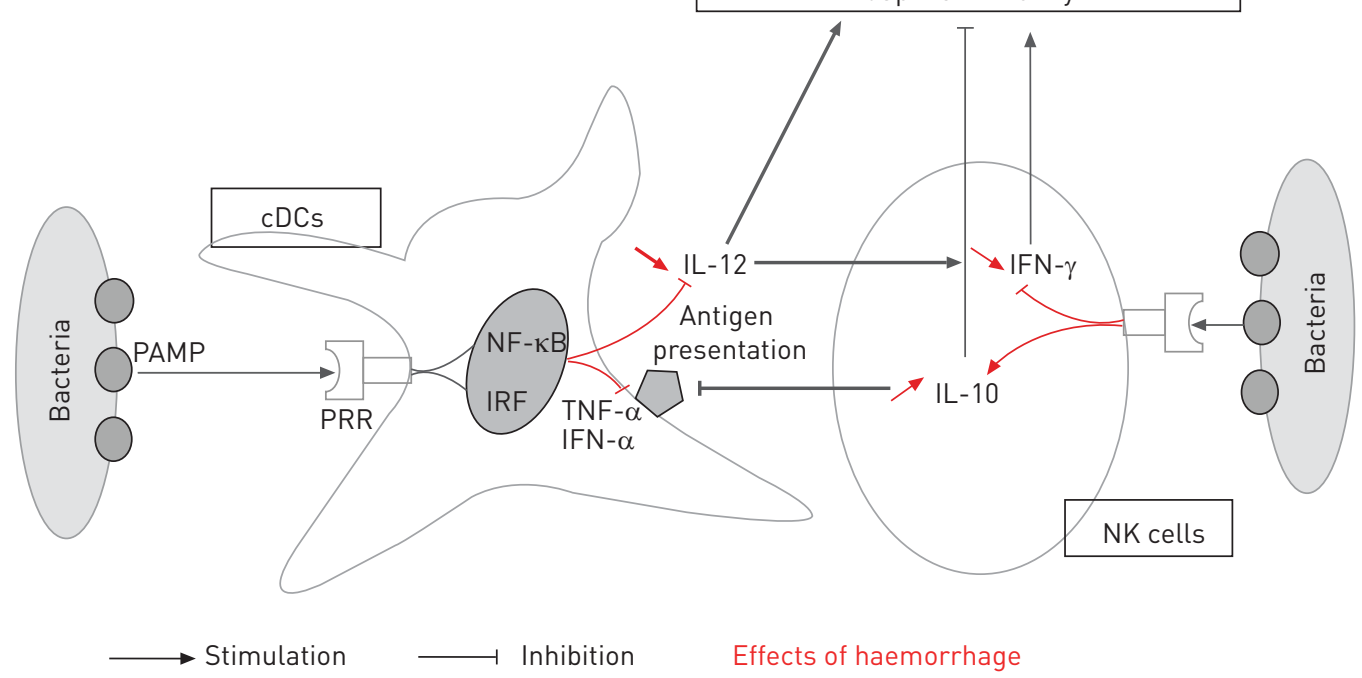

b)

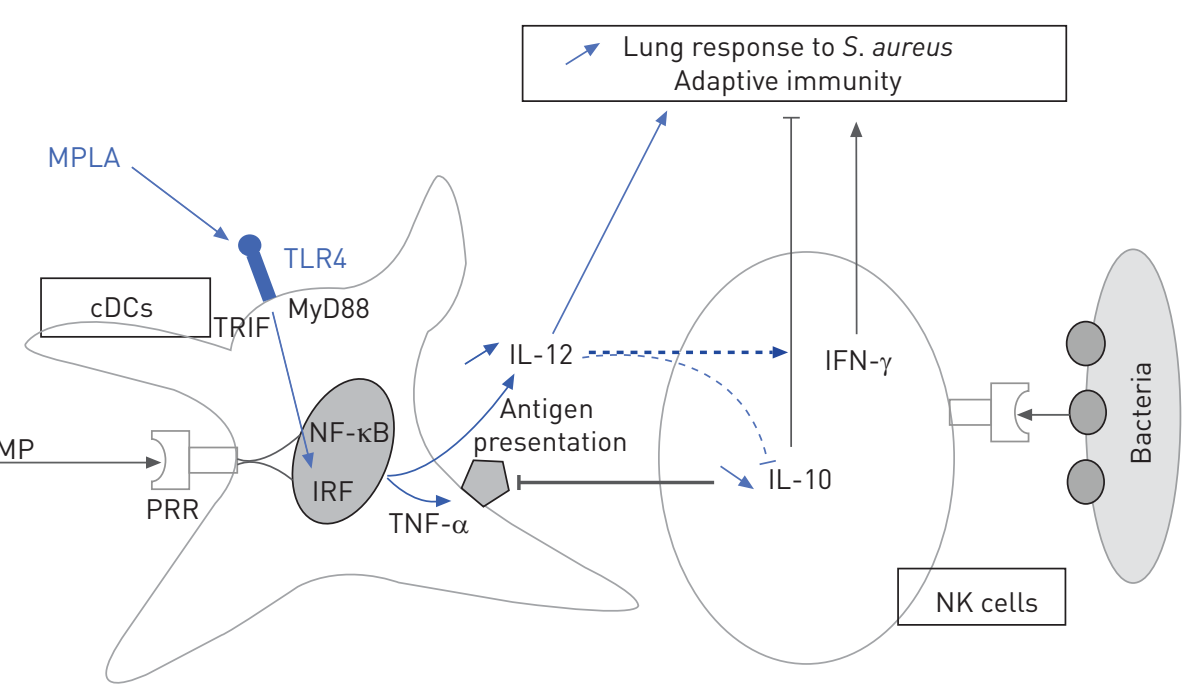

Observed effects of MPLA _..... Hypothesis

FIGURE 8 Schematic illustration of a) the haemorrhage and b) the monophosphoryl lipid A (MPLA) effects on immune response during pneumonia. Recognition of pathogen-associated molecular patterns (PAMP) by pattern-recognition receptors (PRR) generates signals that activate dendritic cells (DCs) and natural killer (NK) cells. Tumour necrosis factor (TNF) $-\alpha$ and interferon (IFN) $-\alpha$ enhance the capacity for antigen presentation of DCs. Regarding NK cells, PRR engagement stimulated anti-bacterial response (IFN- $\gamma$ ) when interleukin (IL)-10 decreased DC functions. a) Haemorrhage decreases both the antigen presentation and the cytokine production by DCs, and drives NK cells toward an IL-10 immunosuppressive response. b) MPLA, a TRIF-biased Toll-like receptor (TLR)4, restores IL-12 production by DCs and prevents the blunting of IL-10 production by NK cells. Finally, MPLA enhances the lung response to post-haemorrhage pneumonia. S. aureus: Staphylococcus aureus; cDC: conventional dendritic cell; NF- $\mathrm{KB}$ : nuclear factor- $\kappa \mathrm{B}$; IRF: interferon regulatory factor.

\section{Conclusion}

In summary, MPLA treatment improved the outcomes of mice undergoing a post-haemorrhage pneumonia, and partially restored the main functions of cDCs, pDCs and NK cells. Ex vivo stimulation of DCs (but not NK cells) with MPLA improved the survival rate of mice in our model. Depletion of NK cells dramatically decreased the survival rate of MPLA-treated mice. Altogether, these results suggest that direct MPLA-stimulation of DCs induces an activation state in NK cells that is critical for the immunocompromised host to fight against extracellular bacteria (fig. 8). 


\section{References}

1 Safdar N, Dezfulian C, Collard HR, et al. Clinical and economic consequences of ventilator-associated pneumonia: a systematic review. Crit Care Med 2005; 33: 2184-2193.

2 Agbaht K, Lisboa T, Pobo A, et al. Management of ventilator-associated pneumonia in a multidisciplinary intensive care unit: does trauma make a difference? Intensive Care Med 2007; 33: 1387-1395.

3 Adib-Conquy M, Asehnoune K, Moine $\mathrm{P}$, et al. Long-term-impaired expression of nuclear factor-kappa B and I kappa B alpha in peripheral blood mononuclear cells of trauma patients. J Leukoc Biol 2001; 70: 30-38.

4 Pulendran B, Tang H, Denning TL. Division of labor, plasticity, and crosstalk between dendritic cell subsets. Curr Opin Immunol 2008; 20: 61-67.

5 Sun JC, Lanier LL. NK cell development, homeostasis and function: parallels with CD8+T cells. Nat Rev Immunol 2011; 11: 645-657.

6 Prass K, Meisel C, Höflich C, et al. Stroke-induced immunodeficiency promotes spontaneous bacterial infections and is mediated by sympathetic activation reversal by poststroke $\mathrm{T}$ helper cell type 1-like immunostimulation. J Exp Med 2003; 198: 725-736.

7 Walzer T. Natural-killer cells and dendritic cells: "l'union fait la force". Blood 2005; 106: 2252-2258.

8 Hedayat M, Netea MG, Rezaei N. Targeting of Toll-like receptors: a decade of progress in combating infectious diseases. Lancet Infect Dis 2011; 11: 702-712.

9 Kanzler H, Barrat FJ, Hessel EM, et al. Therapeutic targeting of innate immunity with Toll-like receptor agonists and antagonists. Nat Med 2007; 13: 552-559.

10 Moretta A. Natural killer cells and dendritic cells: rendezvous in abused tissues. Nat Rev Immunol 2002; 2: 957-965.

11 Roquilly A, Gautreau L, Segain JP, et al. CpG-ODN and MPLA prevent mortality in a murine model of posthemorrhage-Staphyloccocus aureus pneumonia. PLoS One 2010; 5: e13228.

12 Kawasaki T, Fujimi S, Lederer JA, et al. Trauma-hemorrhage induces depressed splenic dendritic cell functions in mice. J Immunol 2006; 177: 4514-4520.

13 National Institutes of Health. Principles of Laboratory Animal Care publication No. 86-23. National Institutes of Health, Bethesda, revised 1985.

14 Asehnoune K, Fitting C, Edouard AR, et al. $\beta 2$-Adrenoceptor blockade partially restores ex vivo TNF production following hemorrhagic shock. Cytokine 2006; 34: 212-218.

15 Pène F, Zuber B, Courtine E, et al. Dendritic cells modulate lung response to Pseudomonas aeruginosa in a murine model of sepsis-induced immune dysfunction. J Immunol 2008; 181: 8513-8520.

16 Venet F, Huang X, Chung CS, et al. Plasmacytoid dendritic cells control lung inflammation and monocyte recruitment in indirect acute lung injury in mice. Am J Pathol 2010; 176: 764-773.

17 Adib-Conquy M, Moine P, Asehnoune K, et al. Toll-like receptor-mediated tumor necrosis factor and interleukin10 production differ during systemic inflammation. Am J Respir Crit Care Med 2003; 168: 158-164.

18 Souza-Fonseca-Guimaraes F, Parlato M, Fitting C, et al. Cell tolerance to TLR agonists mediated by regulatory T cells after polymicrobial sepsis. J Immunol 2012; 188: 5850-5858.

19 Robinson A, Abraham E. Effects of hemorrhage and resuscitation on bacterial antigen-specific pulmonary plasma cell function. Crit Care Med 1991; 19: 1285-1293.

20 Wiggers CJ. Physiology of Shock. New York, Commonwealth Fund, 1950; p. 121-146.

21 Medzhitov R. Recognition of microorganisms and activation of the immune response. Nature 2007; 449: 819-826.

22 Perona-Wright G, Mohrs K, Szaba FM, et al. Systemic but not local infections elicit immunosuppressive IL-10 production by natural killer cells. Cell Host Microbe 2009; 6: 503-512.

23 Segura E, Albiston AL, Wicks IP, et al. Different cross-presentation pathways in steady-state and inflammatory dendritic cells. Proc Natl Acad Sci USA 2009; 106: 20377-20381.

24 O'Neill LAJ, Bowie AG. The family of five: TIR-domain-containing adaptors in Toll-like receptor signalling. Nat Rev Immunol 2007; 7: 353-364.

25 Adib-Conquy M, Adrie C, Moine $\mathrm{P}$, et al. NF- $\mathrm{KB}$ expression in mononuclear cells of patients with sepsis resembles that observed in lipopolysaccharide tolerance. Am J Respir Crit Care Med 2000; 162: 1877-1883.

26 Power MR, Li B, Yamamoto M, et al. A role of Toll-IL-1 receptor domain-containing adaptor-inducing IFN- $\beta$ in the host response to Pseudomonas aeruginosa lung infection in mice. J Immunol 2007; 178: 3170-3176.

27 Fitzgerald KA, Golenbock DT. Immunology. The shape of things to come. Science 2007; 316: 1574-1576.

28 Kang SJ, Liang HE, Reizis B, et al. Regulation of hierarchical clustering and activation of innate immune cells by dendritic cells. Immunity 2008; 29: 819-833.

29 Deniz G, Erten G, Kücüksezer UC, et al. Regulatory NK cells suppress antigen-specific T cell responses. J Immunol 2008; 180: 850-857.

30 Woiciechowsky C, Asadullah K, Nestler D, et al. Sympathetic activation triggers systemic interleukin-10 release in immunodepression induced by brain injury. Nat Med 1998; 4: 808-813.

31 Muehlstedt SG, Lyte M, Rodriguez JL. Increased IL-10 production and HLA-DR suppression in the lungs of injured patients precede the development of nosocomial pneumonia. Shock 2002; 17: 443-450.

32 Souza-Fonseca-Guimaraes F, Parlato M, Philippart F, et al. Toll-like receptors expression and interferon-gamma production by NK cells in human sepsis. Crit Care 2012; 16: R206. 